\title{
COVID-19 and the entrenchment of a virtual elite private school: Rethinking education policies in Zimbabwe
}

\author{
Baldwin Hove ${ }^{1} \&$ Bekithemba Dube ${ }^{* 1}$ \\ 1. University of the Free State, Faculty of Education, South Africa \\ *Corresponding author: dubeb@ufs.ac.za \\ Received : 2021-03-21 \\ Revised : 2021-04-23 \\ Accepted : 2021-05-29
}

d

$10.46303 /$ jcve.2021.5

\begin{abstract}
How to cite this paper: Hove, B., \& Dube, B. (2021). COVID-19 and the entrenchment of a virtual elite private school: Rethinking education policies in Zimbabwe. Journal of Culture and Values in Education, 4(2), 84-94. https://doi.org/10.46303/jcve.2021.5

This is an Open Access article distributed under the terms of the Creative Commons Attribution 4.0 International license (https://creativecommons.org/licenses/by/4.0/)
\end{abstract}

\begin{abstract}
By using a critical emancipatory research framework, this theoretical paper discusses the COVID-19induced commercialisation of the education system in Zimbabwe. It argues that COVID-19 exposed and widened the digital gap between privileged and underprivileged learners, regardless of the learners' geographical location. The digitalisation of the education space -in adherence to World Health Organization's COVID-19 guidelines - has resulted in the creation of virtual elite schools. Learners from privileged families found sanctuary in digital learning, whilst underprivileged learners continue to be exposed to the reality of commercialised education. This trend has revealed educational inequalities between privileged and underprivileged learners. The paper answers two major questions: 1 . What are the inequalities that were reintroduced by the COVID-19 pandemic in the Zimbabwean education system? and 2. How effective is stakeholders' response to COVID-19-induced inequalities? The paper argues that COVID-19 has dashed the hopes of free education for all, by creating a digital gap that perpetuates and entrenches inequalities in relation to learners. In light of these findings, the study suggests that education stakeholders invest in digital infrastructure, with special attention being paid to learners' economic status, as opposed to their geographical location.
\end{abstract}

Keywords: COVID-19; inequality; online education; underprivileged learner; privileged learner.

\section{Introduction}

This theoretical paper discusses the COVID-19-induced commercialisation of the education system in Zimbabwe. It argues that COVID-19 exposed and widened the digital gap between privileged and underprivileged learners, regardless of the learners' geographical location. The COVID-19 pandemic initiated an abrupt and dramatic digital revolution that changed the teaching and learning methodology that had been applied throughout the world (Tam \& El-Azar, 2020). The pandemic required stakeholders to take a digital leap in the education sector. In a very short space of time, teaching and learning was revolutionised. Virtual or digitalised classes took over from traditional physical classrooms. Online 
education became the only viable option to ensure schooling continued in most countries. Governments and education stakeholders were put to work. Various online platforms were designed so that learning did not stop with lockdown. For example, lessons were presented with the aid of radio and television, social media platforms, Blackboard and other learning management systems, Zoom and Skype - which are only some of the alternatives that were used to quickly absorb shocks that accompanied the sudden transition to online education. This revolution meant learners faced a number of challenges, and even opportunities. Ebrahim et al. (2020) report that, by March 2020, schools in 185 countries had stopped face-to-face teaching, thereby affecting 90 percent of the world's students. While many developed nations sailed through the transition to digital learning with ease, the situation in developing countries, like Zimbabwe, was different. Zimbabwe's digitally infrastructure could not support online education. Only an insignificant percentage of the privileged learners could afford to engage in online education. Even though virtual education is an old invention, it was not popular in Zimbabwean primary and secondary schools. People were not ready to engage in online education. Therefore, the transition presented a plethora of challenges.

A variety of reasons are given to explain the complications of online education the world over and in Zimbabwe in particular. According to Kopp (2020), the most common challenges of online education are related to the change from traditional in-person education, the pace of change, access to technology, user competence and financing of online education. Mukute et al. (2020) report that, when the COVID19 pandemic started, concerns about students' ability to adapt to digital learning, arose. The reduction in or total elimination of physical teacher-learner interaction took a toll on learners' performance. Learners most affected are those that are economically disadvantaged, and those whose foundational learning is not strong, particularly girls and children with disabilities. In the absence of the teacher's presence, students are less committed to the integrity of their schoolwork. Some submit half-completed tasks, and independent work is greatly compromised by learners discussing or getting the answers from their friends. The cost of digital infrastructure also presents a major stumbling block, especially for economically disadvantaged learners. Challenges relate mainly to the cost of access, and lack of skill to navigate the digital world.

It is a fact that most learners struggle to adapt to online education, and this fact greatly compromises teaching and learning. This paper examines the various challenges that learners in Zimbabwean primary and secondary schools faced during the COVID-19-induced lockdown in the country. It analyses the role played by the government and private sector in alleviating the challenges.

\section{Literature Review}

Several papers have been written on the challenges posed by and the reactions of stakeholders to the effects of COVID-19 in the education sector the world over, and in Zimbabwe in particular. The key matters raised relate to issues of inequality in the allocation of and access to digital technology. Online education seems to be the common strategy used to respond to the COVID-19-induced closure of schools. This paper reviewed a number of articles in an attempt to understand the challenges and response to the effects of COVID-19 on the education sector. Silumba and Chibango (2020), XinhuaNet (2020), Mandikiana (2020), Dube (2020) and Matimaire (2020), among others, agree that the COVID19-induced problems in education had a similar pattern throughout the world (McCorkle, 2020; Novikov, 2020; Tarman, 2020).

Lockdown and closure of schools were widely used strategies to combat the spread of the deadly disease. Mandikiana (2020) reports that previous pandemics had proven that closing schools prevented the spread of pandemics. This could have influenced worldwide resolutions on lockdowns, social distancing, use of personal protective equipment, as well as quarantining of suspected cases. Pellini et al. (2020, May 11) explain that COVID-19 affected learners worldwide, to the extent that, by the first quarter of 2020, over 180 countries had engaged in lock down of schools, affecting about 1.5 billion 
Hove, B. \& Dube, B. COVID-19 and the entrenchment of a virtual elite private school. Rethinking education policies in Zimbabwe

students, which transforms to $87.4 \%$ of learners globally. Li and Lalan (2020) also state that COVID-19 resulted in the global closure of schools, with over 1.2 billion learners globally being affected by the lockdowns. Dube (2020) reports that the South African government responded to COVID-19 by closing what they viewed as non-essential services, including schools. In Zimbabwe, 4,6 million learners, and 127000 teachers at 9625 schools were affected by the COVID-19-induced lockdown (MoPSE, 2020 as cited in Mandikiana, 2020). Lockdown may have helped to combat the spread of the pandemic; however, it had negative effects on teaching and learning.

In the education sector, lockdown ushered in a new era of online learning, characterised by its own positives and negatives. In his 2020 article, entitled, Rural online learning in the context of COVID-19 in South Africa: Evoking an inclusive education approach', Dube identified a number of challenges that affect online education. These include poor networks, a shortage of digital devices, closure of internet cafes, computer illiteracy in both teachers and learners, and the high cost of data. Research by The World Bank (2020) found that Learners have challenges in accessing online learning; this is particularly true for Learners in underprivileged communities, in households where Internet connectivity is bad or non-existent, learners with little or no prior practice of online education, and/or those learners who are subject to other disadvantages. The World Bank (2020) states, furthermore, that, in practice, the move to online learning benefits mainly students who are already advantaged in various ways, there are greater advantages for privileged students compared to underprivileged students, urban compared to rural students, high-performing compared to poorly performing students, and those from elite families compared to learners from less educated families. Pellini et al. (2020) claim most of the challenges posed by online education were the result of few nations being prepared for the pandemic.

These reports are important, because they show that the Zimbabwean situation is not unique. Underprivileged learners, mainly those in rural Zimbabwe, faced similar challenges. Silumba and Chibangu (2020) and Mandikiana (2020) argue that the underprivileged learner in Zimbabwe was the first to experience the negative effects of schools being closed due to the government-imposed lockdown. Mandikiana (2020) says that, for Zimbabwe and most developing countries in the world, the closing of schools resulted in panic and uncertainty amongst all education stakeholders. Shutting down schools removed the learner from the environment that was required for providing physical, emotional and psychosocial support, and worsened existing challenges faced by the impoverished, disabled, displaced and refugee children (INEE, 2020). An analysis of these texts shows that online education is directly dependent on a learner's economic status. This finding formed the basis of this research, which intended to show that access to education now depends on a leaner's financial status. The free basic education to all policy that the Zimbabwean government adopted after independence in 1980 was now a mere rhetoric.

Dube (2020), Matimaire (2020) and Silumba and Chibango (2020) agree that access to online education demands financial resources. Silumba and Chibango (2020) explain that, in Zimbabwe, elite schools were the first to embrace online learning because they had financial resources. These elite schools adopted online learning platforms, such as G- Suite and Zoom, as platforms for their E-learning programmes (Silumba and Chibango 2020). Underprivileged learners remained locked up by the lockdown while they waited for the government and well-wishers to act. The situation is worse in rural areas, where digital learning is a new phenomenon. Furthermore, in most developing countries, including Zimbabwe, the national infrastructure was not ready to support nationwide online education. Therefore, problems like a shortage of digital gadgets, poor network connectivity, and poverty prevented the majority of learners from gaining access to virtual classrooms. This situation created an education gap between privileged and underprivileged learners.

Pellini et al. (2020) agree with the 2020 World Bank report that education systems of developing countries were the worst affected by the COVID-19 pandemic. Pellini et al .(2020) state the following: 
The digital divide means that internet and mobile network access varies greatly in lowincome countries, for instance access to the internet is over $80 \%$ of the population in some Southeast Asian countries, but as low as $39 \%$ in Vietnam and some African countries. The reality is that online learning will be easier for those with access and will exclude large groups of disadvantaged learners. A large number of learners may have no electricity, some will have a radio but not a television at home, others will have basic feature mobile phones but not smartphones, and others will have only low-bandwidth internet available. (p. 1)

This report explains the online education situation in Zimbabwe, a closer analysis of which exposes that, in developing countries, underprivileged learners are the worst affected by the COVID-19 pandemic, because they cannot afford migration from physical to digital learning. Silumba and Chibango (2020) point out that the government of Zimbabwe and other education stakeholders embarked on online education in its various forms as a response to the COVID-19-induced closure of schools. However, this approach favoured the 'haves' whilst the 'have-nots' were severely impacted, and which created inequalities in the education sector that were reminiscent of colonial times.

Pellini et al. (2020) maintain that, in spite of the relatively low cost of online education, it still required an already established infrastructure. For example, for a learner to access television and radio lessons, there is a need for frequency boosters and receivers. Television and radio lessons are useful for reaching isolated students at low cost. Examples are local programmes in eastern Africa, such as Know Zone in Kenya, and Ubongo Kids in Tanzania. Radio lessons were widely used during the Ebola pandemic when schools were closed to curb the spread of the deadly disease. However, the fact remains that these low cost online learning platforms require an already established infrastructure - this infrastructure does not exist in most rural communities of Zimbabwe. This means underprivileged learners remain locked out of the virtual classroom.

Reviewing these texts helped us to build an argument that COVID-19 promoted the commercialisation and privatisation of the education system in Zimbabwe. Privileged people grabbed the keys to the newly created virtual classroom, which eroded gains realised in the education sector in the time since Zimbabwe gained independence. COVID-19-induced challenges hinder progress in achieving the United Nations Sustainable Development Goals (UNSDG) particularly Goal 4, which aims to "Ensure inclusive and equitable quality education and promote lifelong learning opportunities for all" (Mandikiana, 2020). It is clear that COVID-19 affects the already disadvantaged learner most. The transition to online learning mainly benefited the already advantaged learner. Stakeholders' response to the plight of the poor learner did not improve the situation. The underprivileged learner was locked out of the newly created online private school.

\section{Theoretical Framework}

This paper used critical emancipatory research (CER) to explain COVID-19-induced inequalities and the commercialisation of digital education in Zimbabwe. The cost of accessing digital learning created a virtual 'private school' that barred the educational space to underprivileged learners, regardless of their geographical location. CER is a philosophical offshoot of several traditions, among which Marxism, Habermas's ideas of emancipatory knowledge, as well as Freire's transformative and emancipatory pedagogy. The theory can also be linked to the ideas of $19^{\text {th }}$-century philosophers and enlightenment thinkers such as Emmanuel Kant, a German philosopher, who first talked about critical theory in 1871 (McKernan, 2013). It is generally agreed that CER is a product of Marxism and Marxist thinking.

CER analyses power relations, discrimination and control. CER seeks to critique and challenge, to transform and empower; it is geared towards social justice and heightening the principles of democracy (Nkoane, 2010 as cited by Dube, 2020). In the case of COVID-19 and education in Zimbabwe, the theory 
helps to critique the injustices caused by COVID-19. CER helps to explain interventions that were designed to create equality in the education system. Demirovic (2009 as cited by Dube (2020), explains that CER scholars sought to explain and encourage participation, and to shape the world into a better place for all. In the Zimbabwean education context, CER can be used to create a level education space for all, by condemning the 'eliticisation' of the education space. CER scholars problematise "historical and social conditions of crisis, oppression, inequality and replace them with emancipatory ones" (Sinnerbrink, 2012 as cited by Dube 2020). Therefore, in the Zimbabwean situation, the theory helps to identify and understand the plight of the financially unstable learner, and the effects of commercialised education. It helps to understand the reinvented colonialism, which is represented by social injustice and inequality, particularly in the education sector.

CER is applicable in addressing the challenges of online learning during the COVID-19 pandemic, because it aims to emancipate the underprivileged, such as needy learners, so that they can use their latent energy to change their circumstances (Mahlomaholo, 2013, cited in Dube 2020). CER promotes inclusivity in life changing situations that have the potential to liberate personalities, so that they can get the opportunity to solve their own problems and live life to the fullest while at the same time upholding principles of social justice, inclusion and human rights in the fight against COVID-19 (Dube 2020).

\section{Challenges Caused by COVID -19 in the Education Sector in Zimbabwe}

The pandemic was accompanied by a number of unexpected challenges for the education sector globally. In Zimbabwe, learners and teachers were affected differently, depending on their geographical location, their financial status and their level of computer skills competence. To aid presentation, the challenges are grouped into two broad categories, namely economics-related challenges, and skills competency-related challenges. For example, the cost of accessing digital learning, cost of purchasing digital hardware and cost of buying data are all considered to be economic challenges. On the other hand, inability to operate digital hardware and failure to navigate through online education platforms are viewed as skills competency challenges. This paper shows how learners and teachers are affected by these challenges in the wake of the COVID-19-induced online education. It is important, however, to note that these challenges are interrelated and cannot be discussed in isolation.

\section{Economic challenges and online education}

COVID-19 heightened inequalities between privileged and the underprivileged people. This is because the pandemic came with many unexpected effects. Mandikiana (2020) identifies the closure of schools and the creation of a learning gap as some of the immediate effects of COVID-19, not only in Zimbabwe, but globally. She says this affected about 1,576 billion, 297 million and 4,6 million learners globally, in Africa and in Zimbabwe respectively. This is echoed by statistics from the Zimbabwean Ministry of Primary and Secondary education which shows that besides the 4,6 million learners, the pandemic induced closure of schools also affected 127000 teachers at 9625 schools (MoPSE, 2020 as cited by Mandikiana, 2020). The closing of these schools resulted in a forced transition to online education since it was the only possible option regardless of whether the nation was prepared for it or not.

Already battling with an unstable economy, Zimbabwe was severely affected by the transition. The expense of accessing online education was the major indicator that differentiated privileged from underprivileged learners in Zimbabwe. The transition to online education had serious effects on underprivileged learners in both urban and rural areas. In most developing nations, underprivileged learners struggled to access basic education (United Nations Development Programme 2020). In southern Africa, for example, online education challenges are severe in remote areas with limited resources, areas that lack internet connectivity, and have high computer illiteracy rate (Dube 2020). Learners in Zimbabwe, as in other developing countries, face serious challenges, and those that are 
Hove, B. \& Dube, B. COVID-19 and the entrenchment of a virtual elite private school. Rethinking education policies in Zimbabwe

underprivileged are the worst affected. Underprivileged learners in both rural and urban settings struggle to access digital learning. While privileged learners also experienced the effects of the absence of a physical classroom, they could afford the migration to digital learning, which lead to the commercialisation of virtual learning, because only the advantaged could afford to access to online education.

Literature shows that there is a deficit of digital infrastructure in Zimbabwe. The economic woes Zimbabwe has experienced since the turn of the millennium could be one of the reasons why the nation failed to fully invest in digital technology. According to the International Telecommunication Union (2020), by the year 2017, only $27.055 \%$ of the Zimbabwean population had access to an internet connection. Mudzingwa (2020, as cited by Matimaire, 2020), reveals that, at the peak of the COVID-19 pandemic, only 2864 schools of the nearly 9000 schools in Zimbabwe had internet access, that is about $32 \%$ of the schools. MoPSE (2020) estimates the internet connectivity rate at $26.25 \%$ for primary schools and $42.76 \%$ for secondary schools. In the year 2019 , the computer-to-learner ratio in Zimbabwe was 1:32 (MoPSE, 2020) - this ratio is high, and it presents challenges related to the accessibility of online education. Furthermore, more than half the schools with internet access are in urban areas, leaving rural areas with a very small fraction of the connectivity percentage. Also of concern is that, even in urban schools with internet connection, the internet is seldom fully utilised, because of problems related to power outages, which greatly affect the availability and strength of the internet signal.

These drawbacks reflect the low application rate of online learning in Zimbabwe. It means that the majority of learners were not exposed to computer education before the closure of schools. The shortage of computers at schools has a direct effect on the computer literacy rate of learners. It means the burden of acquiring digital hardware and the cost of acquiring computer skills so as to be able to enrol in online education remains on the shoulders of the learner. This situation presents a bumpy road for online education, particularly for underprivileged learners who struggle to fund the basics needed for day-to-day survival, and leads us to argue that the commercialisation of online education created online schooling for only the elite.

Generally, Zimbabwe lags regarding the availability of Information Communication Technology (I.C.T). Despite adopting a national ICT policy in 2005, the nation still trails behind in practical implementation of the policy, to the extent that the 2020 COVID-19 pandemic found the nation unprepared. The Progressive Teachers Union of Zimbabwe (PTUZ) president, Takavafira Zhou, lamented the lack of digital infrastructure in Zimbabwe. Zhou is quoted by Matimaire (2020) saying, "Other than WhatsApp, elearning is out of reach for many students due to challenges with internet connectivity, let alone affordability". Zhou further says that E-learning has limited applicability, due to limited electrical power in rural Zimbabwe, and incessant power cuts in major cities. "Currently more than 65\% of secondary schools are not electrified, while more than $75 \%$ of primary schools are not electrified. Several schools have no single computer or laptop and it will take a responsible government to ensure that these challenges are addressed", said Zhou, adding that in-service training for teachers is needed.

This quotation explains the ICT situation in the Zimbabwean education sector. It points to issues related to the cost of accessing online learning and it explains the digital infrastructure deficit in the country. Therefore, it can be argued that the COVID-19 pandemic worsened an already pitiable situation. It is lamentable that, due to the deficit of digital infrastructure, the already limited ICT resources end up being accessible only to a privileged few, because they have the financial resources to pay for it. Underprivileged learners, especially those in rural Zimbabwe, may never be able to access online learning. This is the reason why the central argument of this paper relates to the commercialisation of education in Zimbabwe.

The economic miseries of underprivileged learners in both rural and urban communities in Zimbabwe make it impossible for them to afford digital hardware like smart phones and other devices that can 
enable them to access the internet. They do not have the financial resources needed to access elearning portals. This means there is a wide digital divide between privileged and the underprivileged learners. MISA Zimbabwe legal and ICT policy officer, Nompilo Simanje, mentioned that high data charges, low internet coverage and lack of technical skills by teachers and learners to utilise digital Applications for online learning remain the major stumbling blocks on the road to advancing the edutech revolution (Matimaire, 2020). Silumba and Chibango (2020) discovered that most teachers and learners struggle to buy WhatsApp bundles, which they need to work online.. The price of data bundles added salt to the wounds of underprivileged learners. According to Masarakufa (2020), the cost of unlimited monthly data in Zimbabwe is roughly, USD 50 across all internet service providers. Matimaire (2020) argues that, technically, the cost of data impinge on the affordability of internet services, yet internet is the key component of online learning. Such costs place internet access beyond the reach of many people, for example, Teachers, who are the majority of Zimbabwe's formal employees, earn only about USD 40 in June 2020. Therefore, access to online learning remains a dream for the underprivileged learner in Zimbabwe. This leaves the learner with no option but to adopt the wait-and-see strategy until the pandemic is over, and access to the physical classroom is possible again. It implies that underprivileged learners continue to get the short end of the stick, because they cannot afford the digital resources needed for effective learning during the COVID-19 induced lockdown. Therefore, government policy on the provision of basic education for all remains a myth. Instead, the eliticisation of the education sector is the new reality.

Financial resources determine the quality of education a learner could access during the COVID-19 lockdown in Zimbabwe. Several online platforms gave learners access to education, but access to all those platforms needed some form of financial resources, which meant that learners were now grouped according to their financial status. One group was underprivileged learners, who were in total lockdown, because they have no means to access any of the online education platforms. Another group comprised middle-class learners, who could afford a moderate degree of access, for instance, they could listen to the radio or to television lessons, but could not afford data or a smartphone for interactive learning. Then, was the elite group that could afford access to all online education platforms. This group could afford smartphones, tablets, laptops and data, and have unlimited access to online education. This means that the three categories of learners receive education in different quantities and of different qualities. The best quality education was obviously being accessed by learners with unlimited access, whilst the first group remained in total lockdown.

\section{Skills Competency as a Challenge in Accessing Online Education}

The proportion of teachers and learners who are computer literate determines the effectiveness of digital resources in online education (Kalimullina et al., 2021). This is because the use of digital technology requires some skill and training, especially for new users. According to the Ministry of Primary and Secondary Education (MoPSE, 2020) records, the computer-to-learner ratio in Zimbabwe stood at 1:32: an average of 32 learners have to share one computer. Without even considering variables that could increase the ratio, it is already clear that there was a serious shortage of computers in Zimbabwean schools at the time the report was compiled. This obviously means that most learners had limited access, or did not have access to computers at all. Therefore, there is a good chance that the greater percentage of learners are computer illiterate. It will be unjust to expect such a population to be able to effectively utilise online learning resources, even if they were to be exposed to those digital resources. The situation was worsened by the failure to train teachers on online education. Silumba and Chibango (2020) discovered that most teachers depended heavily on social media platforms, like WhatsApp and Facebook, to continue teaching learners in the lockdown period. These social media platforms were relatively cheap and easy to use. However, still learners needed money to buy data to use these social media platforms and, because of the lockdown, most families that depended on the informal sector for their income, found it very difficult to survive. Considering teachers' meagre salaries, 
Hove, B. \& Dube, B. COVID-19 and the entrenchment of a virtual elite private school. Rethinking education policies in Zimbabwe

they could not afford to buy data either. A combination of computer illiteracies and poverty meant that online education was never an option for underprivileged learners. Computer illiteracy was a major drawback to most interventions designed by stakeholders to rescue underprivileged learners from the lockdown.

\section{Stakeholder Response to Online Education}

It is important to highlight that stakeholders, particularly the government, the private sector and nongovernmental organisations (NGOs), did not turn a blind eye to ever-increasing education challenges. Mukute et al. (2020) report several responses to the new challenges that ensured that learning never stops. Countries in the Southern African Development Community (SADC) planned to mobilise resources, implement context-appropriate and equitable solutions for the challenges facing distance education, and for learning remotely. Dube (2020) mentions that private stakeholders, like Higherlife Foundation, played a critical role in the provision of digital learning in Zimbabwe through the Ruzivo programme. However, Matimaire (2020) maintains that, in Zimbabwe, just like in most African countries, the migration to digital learning remained theoretical rather than practical. This is clearly revealed by contradictory responses by the government and teacher unions, like the PTUZ, to MoPSE claims regarding their preparedness to handle the effects of COVID-19 at schools (XinhuaNet, 2020).

\section{Interventions by the Private Sector}

Private companies and NGOs were among the noticeable actors that came up with alleviating strategies to help learners migrate to online learning. Telecoms giant Econet Wireless, through its subsidiaries Cassava Smartech and Higherlife Foundation, is one of the organisations that actively continued and expanded online learning. Mudzingwa (2020, as cited in Matimaire, 2020) reports that Cassava Smartech launched Akello Digital Classroom and Akello E-Library, these platforms enable learners to enrol in online classes and get access to a variety of online resources and books approved by the Zimbabwe School Examinations Council and other international examination boards. Higherlife Foundation has a rich history of helping underprivileged learners. It invests in 20000 learners annually and has supported more than 350000 learners through Orphans and Vulnerable Children and meritbased scholarships in the last 24 years in Zimbabwe (MoPSE, 2020). Through the Ruzivo project, Higherlife Foundation continues to offer relatively inexpensive access to online education resources. These were among the national programmes that touched every corner of Zimbabwe, and thereby generally helping underprivileged learners. However, though the private sector jumped in to rescue the situation, we cannot ignore the fact that there are still gaps that could not be bridged. Organisations provided resources such as tablets, laptops, compact discs and online libraries, which were useful, but in some cases these resources demanded complementary use of physical digital infrastructure. For example, accessing the Ruzivo online library requires a mobile data network, and not all learners were located in areas with mobile networks. Not all learners could afford the subsidised data bundles. Not all learners were sufficiently computer literate to navigate the digital platforms they were exposed to in a short period of time. The argument that online education created an elite school remains valid. Without undermining the efforts of the private sector, we still suggest that the nation should revolutionise the education sector by embarking on nationwide digital infrastructure construction. Such an initiative will unlock the online private schools for all, and boost national education standards.

In addition to Econet Wireless, several NGOs, such as World Vision, Care International and Mavambo Orphan Care, stepped in to help learners migrate to online education. Some distributed radios, some sponsored digital resources and some partnered with the government in various activities. Dzinamarira and Musuka (2020) refer to a WhatsApp platform for remote teaching that was launched by UNESCO. They argue that the application can reach and be utilised by more than 5,2 million people WhatsApp users in Zimbabwe. Such digital platforms have the capacity to ensure continued learning for learners who are in home isolation. It helped underprivileged learners to access education during the lockdown 
Hove, B. \& Dube, B. COVID-19 and the entrenchment of a virtual elite private school. Rethinking education policies in Zimbabwe

period. However, unfortunately, access to the sources of education provided still required some form of financial stability. For example, learners needed smartphones to access the UNESCO WhatsApp platform, they needed electricity, a network and a radio receiver to listen to the radio lessons.

During lockdown, education was no longer a matter of walking into a classroom. The monetary value attached to the digital resources needed to access education in the COVID-19 lockdown period obliges us to argue that education was now reserved for financially stable learners. It locked underprivileged learners out of the classroom, because, in place of face-to-face schooling, a virtual private school that was accessible only to those with money, had been created.

\section{Government Interventions}

The major contribution of the government of Zimbabwe to online education was the reintroduction of radio and television lessons. Such programme should reach out to learners who lacked internet access, and it has the advantage of using existing infrastructure (Pellini et al., 2020). Radio and television lessons had been operational for decades, and were popularly referred to as 'schools broadcasts' in the 1980s (Chikasha, 2012). With the coming of the COVID-19 pandemic, the MoPSE, with support of UNICEF Zimbabwe, Education Cannot Wait (ECW) and Global Partnership for Education (GPE), intensified the launch of radio lessons programming in June 2020, starting with the primary level. Learning areas covered include mathematics, indigenous languages, English, science and technology, and heritage studies. The introduction of the radio lessons served as a commitment by government to ensure that learning does not stop during the COVID-19-induced school lockdowns (UNICEF, 2020). Primary and secondary school teachers were tasked to produce lessons for their specific subjects. Each province was assigned specific subjects and grades for the production of audio and video lessons. This work cascaded down to districts, clusters and schools. The recorded lessons were forwarded to the responsible district offices, where the best lessons were selected and then forwarded to the provincial offices, and to headquarters for broadcast on national radio and television.

In theory, this was a major step towards bridging the transition from the traditional school to online education. However, in practice, the intervention faced serious implementation and viability challenges. The intervention was based on the assumption that the national broadcasters covered the whole country; in reality, the radio and television signal is mainly concentrated in urban areas. Some areas, like Plumtree, Beitbridge and Binga, among other outlying areas, have never received a Zimbabwean television signal. The radio signal in those areas is relatively poor. The situation was worsened by community radio stations still being in their infancy, and not spared the economic woes affecting the whole country. Even in those areas where the radio and television signal was good, power interruptions rendered the whole programme less effective.

UNICEF, (2020), reports that, despite the potential of the campaign to benefit some families, a radio receiver is beyond the reach of many, and poses a challenge to supporting children to catch up with lessons. Such challenges mean that it was mainly families with a backup power service, and those with some degree of financial stability that could access the lessons. Therefore, one may argue that online education was not poor-friendly - poor people remained locked out of the classroom. Government interventions did not serve the intended purpose, instead, they entrenched the privatisation of remote education. It can be suggested that, for equality in online education to be achieved, the government should invest in public multipurpose digital infrastructure. Opening up the media through licensing of community radio stations is a step in the right direction. Capacitating radio stations and licensing community television stations can be advantageous to underprivileged learners, even after the COVID19 era. 
Hove, B. \& Dube, B. COVID-19 and the entrenchment of a virtual elite private school. Rethinking education policies in Zimbabwe

\section{Conclusion}

The paper analysed the economic effects of the COVID-19 pandemic on the provision of education in Zimbabwe. It argues that the sudden COVID-19-induced lockdown that resulted in unplanned closure of schools in March 2020 left underprivileged learners exposed to the inequalities embedded in online learning. The need to migrate to online learning was a slap in the face for underprivileged learners, because the digital resources for needed for online learning are expensive. Government promises seldom materialised, thus, leaving underprivileged learners in education lockdown. This created a 'virtual private school', where learners who afford digital resources could automatically enrol and join a world-class classroom with access to quality learning and a wide variety of educational resources. Undoubtedly, the COVID-19 pandemic resulted in the commercialisation of education. Attempts by stakeholders to rescue underprivileged children did not yield significant results. This failure was the result of the nation's physical infrastructure not being compatible with the number of users and the demands of online education. It is suggested that the government and other education stakeholders invest in modern technology that promotes online teaching and learning beyond the COVID-19 era.

\section{Funding information}

This study was funded and supported by National Research Fund Research Grant: TTK200318509938

\section{References}

Chikasha, A. (2012). The rise and fall of educational radio in Zimbabwe: the forgotten medium and technology. Retrieved from https://www.semanticscholar.org/paper/The-rise-and-fall-ofeducational-radio-in-Zimbabwe

Dube, B. (2020). Rural Online Learning in the Context of COVID-19 in South Africa: Evoking an Inclusive Education Approach. Multidisciplinary Journal of Educational Research, 10(2), 135-157. https://doi.org/10.4471/remie.2020.5607

Ebrahim, S. H., Ahmed, Q. A., Gozzer, E., Schlagenhauf, P., \& Memish, Z. A., (2020). Covid-19 and community mitigation strategies in a pandemic. BMJ, 2020(368), 1066. https://doi.org/10.1136/bmj.m1066

INEE (Inter-Agency Network for Education in Emergencies). (2020). Technical Note: Education during the COVID-19 pandemic. INEE, New York, USA. Retrieved from: https://inee.org/resources/inee-technical-note-education-during-covid-19pandemicInternational Communications Union. (2019). Measuring digital development: Facts and figures 2019. ITU Publications.

Kalimullina, O., Tarman, B. \& Stepanova, I. (2021). Education in the Context of Digitalization and Culture: Evolution of the Teacher's Role, Pre-pandemic Overview. Journal of Ethnic and Cultural Studies, 8(1), 226-238. DOI: http://dx.doi.org/10.29333/ejecs/629

Kopp, W. (2020, June 22). Lessons from this worldwide experiment with distance learning. Teach for All [Blog]. https://medium.com/teach-for-all-blog/lessons-from-this-worldwide-experiment-withdistance-learning-da9ed171ad

Li, C., \& Lalan, F. (2020, April 29). The COVID-19 pandemic has changed education forever. This is how. World Economic Forum. https://www.weforum.org/agenda/2020/04/coronavirus-educationglobal-covid19-online-digital-learning/

Mahlomaholo, S. (2009). Critical emancipatory research and academic identity. Africa Education Review, 6(2), 224-237.

Mandikiana, M. R. V. (2020). Rethinking Zimbabwean education during and beyond the COVID-19 pandemic. Quest Journal of Management and Social Sciences, 2 (2), 290-306.

https://doi.org/10.3126/qjmss.v2i2.33302 
Hove, B. \& Dube, B. COVID-19 and the entrenchment of a virtual elite private school. Rethinking education policies in Zimbabwe

Masarakufa, C. (2020, May 2). Comparative analysis of internet connectivit options in Zimbabwe. StartupBiz.co.zw. https://startupbiz.co.zw/comparative-analysis-of-internet-connectivityoptions-in-zimbabwe/

Matimaire, K. (2020). Digital-shy Zimbabwe's schools feel the brunt of COVID-19. https://africaninternetrights.org/sites/default/files/Kenneth\%20Matimaire-1.pdf

McCorkle, W. (2020). Problematizing Immigration Restrictions during COVID-19 in the Social Studies Classroom. Research in Social Sciences and Technology, 5(3), 1-24. https://doi.org/10.46303/ressat.05.03.1

McKernan, J. A. (2013). The origins of critical theory in education: Fabian socialism as social reconstructionism in nineteenth century Britain. British Journal of Educational Studies, 61(4), 417-433.

MoPSE (2020). (Ministry of Primary and Secondary Education). Zimbabwe COVID-19 preparedness and response strategy. Education Cluster Strategy, Government publications.

Mukute, M., Francis, B., Burt, J., \& Souza, B. (2020). Education in times of COVID-19: Looking for silver linings in southern Africa's educational responses. Southern African Journal of Environmental Education, 36.

Nkoane, M. M. (2013). Creating sustainable postgraduate supervision learning environments through critical emancipatory research. TD: The Journal of Transdisciplinary Research in Southern Africa, 9(3), 393-400.

Novikov, P. (2020). Impact of COVID-19 emergency transition to on-line learning onto the international students' perceptions of educational process at Russian university. Journal of Social Studies Education Research, 11(3), 270--302. Retrieved from https://jsser.org/index.php/jsser/article/view/2602/468

Pellini, A., David, R., Jordan, K., \& Phillips, T. (2020, May 11). Education during the COVID-19 crisis Opportunities and constraints of using EdTech in low-income countries [Policy brief]. UKFIET, The Education and Development Forum. https://www.ukfiet.org/2020/education-during-thecovid-19-crisis-opportunities-and-constraints-of-using-edtech-in-low-income-countries/

Silumba, C., \& Chibango, S. (2020). Online education in promoting continued education during Coronavirus outbreak in Zimbabwe: 'Challenges and solutions'. Asian Journal of Interdisciplinary Research, 3(4), 74-88. https://doi.org/10.34256/ajir2047

Tam, G., \& El-Azar D. (2020, March 13). 3 ways the coronavirus pandemic could reshape education. World Economic Forum. www.weforum.org/agenda/2020/03/3-ways-coronavirus-isreshaping-education-and-what-changes-might-be-here-to-stay/

Tarman, B. (2020). Editorial: Reflecting in the shade of pandemic. Research in Social Sciences and Technology, 5(2), i-iv. https://doi.org/10.46303/ressat.05.02.ed

UNDP (United Nations Development Programme). (2020). Human development perspectives Covid-19 and human development: Assessing the crisis, envisioning the recovery. Retrieved from http://hdr.undp.org/sites/default/files/covid-19_and_ human_development_0.pdf

UNESCO (2020, March 24). COVID-19 educational disruption and response. Retrieved from https://en.unesco.org/news/covid-19-educational-disruption-and-response

UNICEF. (2020). ZBC radio lessons programme schedule. UNICEF Zimbabwe. Retrieved from https://www.unicef.org/zimbabwe/zbc-radio-lessons-programme-schedule

World Bank. (2020). Remote learning, EdTech and COVID-19. https://www.worldbank.org/en/topic/edutech/brief/edtech-COVID-19

XinhuaNet. (2020, May 29). Zimbabwe's COVID-19 cases climb to 149, adding 17. XinhuaNet. http://www.xinhuanet.com/english/2020-05/29/c 139098680.htm 